\title{
FACTORS OF HIGHER EDUCATION INSTITUTIONS RANKING (COMPARISON OF THREE WORLD UNIVERSITY RANKINGS)
}

\author{
Nattapong Techarattanased \\ Pleumjai Sinarkorn
}

Suan Sunandha Rajabhat University, Bangkok, Thailand

\begin{abstract}
Many universities have drawn attention to world university rankings, which reflect the international competition of universities and represent their relative statuses. This study does not radically contradict all types of global university rankings but calls for an examination of the effects of their indicators on the final ranking of universities. This study investigates the indicator contribution to the ranking of universities in world university ranking systems including the Academic Ranking of World Universities (ARWU), Times Higher Education (THE), and QS World University Rankings. Results showed that in the ARWU system, three indicators regarding faculty members who won Nobel Prizes and Fields Medals and papers published in Nature and Science and in the Science Citation Index and Social Science Citation Index journals predicted the ranking of universities. For the QS and THE systems, the more powerful contributors to the ranking of universities were expertbased reputation indicators.
\end{abstract}

Keywords: world university rankings; ranking indicators; indicator contribution; ranking of universities; university position

\section{Introduction}

Ongoing globalization has already made higher education massively accessible for all (Altbach, 2012). Thus, university rankings and leagues are also gaining considerable importance since millions of potential students and their families are relying on their information.

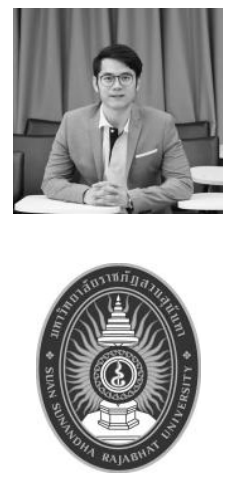

NattapongTecharattanased

Doctor of Business Administration (Marketing Management)

Lecturer at Faculty of Management Science, Suan Sunandha Rajabhat University.

Research interests: marketing, management and innovation

E-mail: nattapong.te@ ssru.ac.th

Pleumjai Sinarkorn

Researcher in Suan Sunandha Rajabhat University, Bangkok, Thailand

Research interests: innovative management, innovative economy, creativeness and business

E-mail: pleumjai.si@ssru.ac.th 
As all the rankings claim accountability and objective evaluation, they are enjoying truly global popularity. Moreover, both international and national ratings are not only growing extensively, but they are also becoming more specialized. Some of them focus on research performance, others are based on institutions' reputation and so on (Rauhvargers, 2011). In this particular article we would like to consider the world university rankings as for many people they are the key parameter of academic excellence in both international and local contexts.

Positive correlation between web links and ranking places have been proved in literature several times, for example, by Lo (2011). Thus, universities themselves are interested to be included into the global ranking activities and achieve higher ranks so that also to achieve greater visibility for all potentially involved stakeholders (Hazelkorn, 2014). For this and other reasons, global rankings are often presented as "a mechanism of agenda setting" with its own and unique soft power (Lo, 2011. 216). On the other hand, they can be also presented as the "integral part of [the] status culture" in the sector of higher education (Marginson, 2014, p. 45). In simple terms, the higher is the ranking of a particular institution, the more visibility it gets. Thus, it also gets extra opportunities to get more students, including international ones. Additionally, the world university rankings often serve as a competitive measurement of institutional performance which includes, inter alia, bibliometric indicators (Huang, 2011).

To some extent, world university rankings can even predetermine stakeholder choices and investment volumes. More, they influence upon changes in institutional benchmarks, restructuring and reorganization of higher education institutions and professional reputation of academic staff members (Hazelkorn, 2009). A study carried out by Bastedo and Bowman (2011) has linked university rankings with their capacity to obtain additional financial resources. In terms of student enrollment, global rankings have enough ability to shape student preferences and predetermine some of the choices being made. The report prepared by the QS (2015) shows that more than $70 \%$ of the surveyed university students consider rankings to be quite important in the university selection process. Moreover, global rankings tend to play much greater role as compared to national or regional rankings. The absolute majority of students believe that higher ranked institutions indeed have better reputation and stronger results in terms of academic excellence.

The world university rankings also have the power to influence the strategic decisions made by the top higher education administrators, including those already affiliated to the leaders in higher education sector (Hazelkorn, 2009). Universities which already have higher ranks can be seen as some sort of institutional sponges that absorb both state funding and private investments. Institutional reputation predetermined by high enough global rankings also makes it easier for universities to attract the best researchers (including those from abroad) and also to get the smartest students, both local and foreign. Generally speaking, international rankings serve as the key provider of institutional reputation and greater perceived credibility. Even further, global rankings of universities demonstrate to have an effect on graduates' future wages (Carroll, 2014) as graduates from prestigious universities and colleges can often expect higher starting salaries, even if they are at the similar positions with the graduates from less famous universities.

For all these reasons described briefly above, many universities are doing their best to plan and implement their institutional performance in strict accordance to the criteria of the world university rankings. At the same time, we also need to mention that today the world 


\section{FACTORS OF HIGHER EDUCATION INSTITUTIONS RANKING}

university rankings have already raised some controversies: they tend to neglect societies' needs, there is an obvious preference to publications in English as the key research indicator, unfairly much attention is paid to natural sciences and medicine, survey indicators as well as expert opinions are often very much subjective if not biased and so on.

In other words, concentrating on solely university rankings and them alone would be extremely risky for universities themselves and for students too! Increasingly frequently students and their parents decide in favor of a particular institution not because of its outstanding academic performance, but only because it is famous enough and has overall good reputation.

Another factor which gets quite a lot of criticism is that university rankings are mostly about research publications indexed by international databases, Web of Science and Scopus in the first place. However, there might a great deal of overvaluing when it comes to such indicator as it is well explained in. Proulx (2007) actually came up with a good notion to describe this phenomenon - the "I-idolization" which is overemphasizing on the most known publication indices. Moreover, Proulx (2007) grounded and explained how ranking results based on SCI and SSCI indexations only force top management of the universities pay too much of attention to research publications while many other aspects of good university education tend to be nearly fully neglected or undervalued.

In terms of academic recognition, another interesting trend (also contributing to subjectivity and bias) is marginalization of the humanities and social sciences in what concerns institutional image of universities (Deem, Mok, \& Lucas, 2008; Delgado \& Weidman, 2012).

All of these factors described above contribute to the growing pressure which intensifies competition between universities and between countries as well. Universities are competing internationally for both human and financial resources, therefore, their institutional behavior is to a great deal predetermined by the global ranking results. On a deeper and more specific level, several studies have also demonstrated the relationship between the indicators used in a particular ranking system and the ranking of universities according to this system, that is, which indicators specifically have greater influence on the ranking of universities. Understanding the role of specific indicators within global rankings is vitally important in understanding the role of global ranking methodologies as well a subsequent strategies' development of the universities pursuing higher ranks in these rankings.

This paper is aimed to investigate the contributions of particular indicators to the ranking of institutions on the examples of three most well-known university ranking systems: the Academic Ranking of the World Universities (ARWU) developed in China; the Times Higher Education Ranking (commonly known worldwide as THE); and the Quacquarelli Symonds' Ranking (mostly known as just QS).

Our research study has been aimed to explore whether the weights of specific indicators in these three global ranking systems are different from the assigned weights as per their methodologies, and whether some of these indicators matter more than the others. We start with describing the methodologies of these three rankings and also present the most common criticisms available in their regard. We proceed with analysing the contributions of the selected indicators into the rankings so that explain all the practical implications they bear. 


\section{Three Global Rankings of Universities: Key Features And Common Criticism}

The ARWU, THE, and QS are frequently referred to as the "big three" in higher education sector (Hazelkorn, 2014, p. 17). All three are equally and vitally important for scholars, administrators, policy makers, and students. The first of these three was ARWU, it was initiated back in 2003. The next year already, the Times Higher Education and the Quacquarelli Symonds Company copublished their ranking, which was then known as THEQS. Interestingly, in 2010, these two ended their collaboration and separated into two different rankings.

All three rankings do not actually have narrowly defined target groups. Anybody interested in current development of the international higher education becomes part of their audience. Thus, these three rankings are able to influence and change the perceptions and selection behaviours of individuals -- students, their parents, faculty members, state and local authorities, community members and who else.

All three rankings use data obtained from the surveys and other local/national resources and of course university profiles. Also, they use databases of research publications and citations. This means that the bibliometric method is partially involved in the ranking process. More specifically, QS uses Scopus data on publications and citations, while the other two rankings prefer Thomson Reuters' Web of Science database. ARWU also collects data from several other important websites (on Nobel laureates, for example), while THE and QS conduct the so-called reputation surveys.

All three rankings publish their results online as ordinal ranking lists. ARWU publishes the list with top-500 institutions: the universities are first ranked from 1 to 100 and later are grouped as 101-150, 151-200, 201-300, 301-400, and 401-500.

The QS still uses the methodological framework from the original version of the THEQS rankings. It publishes the list of top-700 universities; top-400 institutions are ranked separately and the rest of 300 are grouped together.

THE releases an online table of top-400 universities: all up to 200 are singled out and the rest are grouped as 201-225, 226-250, 251-275, 276-300, 301-350, and 351-400.

Each of these rankings uses its own standards for evaluation and weighting of indicators. As we've already mentioned, in 2011, THE ended its collaboration with QS and thus had to develop own methodology, choosing a different partner and the key competitor of Scopus (which is actively cooperating with QS) -- Thomson Reuters. Therefore, instead of the previous 6 indicators that QS is still using, the new methodology by THE consists of already 13 indicators, widely ranging from teaching and research to knowledge transfer.

The dimension of education quality is determined by one indicator only, but a serious one - the number of alumni who eventually got the Nobel Prize or Fields Medals (coded in the ranking as Alumni). This indicator contributes as much as $10 \%$ to the overall rank.

Secondly, the dimension of faculty quality is evaluated by two indicators: the first one is again related to Nobel Prizes and Fields Medals to faculty members (now coded as Award), and the second one is HiCi. This is the parameter related to the most highly cited researchers in 21 subject categories. These two indicators take $20 \%$ each. 


\section{FACTORS OF HIGHER EDUCATION INSTITUTIONS RANKING}

Third, the research output dimension is again determined via two indicators: the papers published in the most known journals -- Nature and Science (coded as NS) and also those indexed in the SCI and SSCI databases (coded as PUB). These two indicators also weight $20 \%$ each. Finally, the per capita performance of an institution (abbreviated as PCP) contributes another $10 \%$ to the overall rank.

The THE system uses 13 indicators grouped in five dimensions. The first one is the teaching dimension. It has quite a significant weight of $30 \%$ and has five indicators, namely, teaching reputation survey, staff-to-student ratio, doctorate-to-bachelor ratio, doctorate awards by an institution, and institutional income scaled against academic staff numbers. The second dimension is research; it also has the $30 \%$ share. It is calculated via research reputation survey, research grants, and the quantity of papers published in academic journals. The third goes the dimension of citation impact, again, 30\%. The fourth dimension is industrial funding for university research; it contributes only $2.5 \%$ to the overall score though. Finally, the international dimension has the weight of 7.5\%. It is determined through the following parameters: the international-to-domestic student ratio, international-todomestic staff ratio, and the number of internationally coauthored research papers.

The QS is still using the original methodological framework, once developed in collaboration with THE. There are six indicators in it, the most important among them is the academic peer reputation survey, its weight is quite significant -- $40 \%$. There is also another reputation survey, addressed to employers. However, it contributes only $10 \%$ to the overall ranking. Then go the indicator of citations per faculty and the faculty-student ratio, both contributing $20 \%$ to the overall score.

Finally, the number of international students and faculty indicators has both the weight of 5\%. It would be appropriate here to note the similarities in these ranking systems; differences though concern the weights of the mentioned above indicators. In the opinion of Proulx (2007), today all university rankings should the approach of "one-size-fits-all" as it often leads to biased and distorted results (p. 76).

Comparable and standardized tables offered by these global university rankings are often perceived, by the uninformed public as the absolutely truthful information. Using such tables, nearly anyone can easily interpret and compare the ranks of the selected universities. Those who make these rankings public also believe that these results reflect the proper position and quality of education at universities as the process of evaluation seems to be quite rigorous (Rauhvargers, 2011).

However, "the objectivity does not ensure that the measures actually chosen are always appropriate", since the weights of the chosen indicators depend on the significance preset by the selected consultants. In simple terms, the ranking systems tend to favor those indicators that are "suitable" for their own purposes, and this factor often jeopardizes institutional or national interests (Marginson, 2014. 46).

Let's take ARWU as an example. Its initial purpose has been understanding the actual global standing of Chinese universities. For this reason, its ranking system focuses on research performance while teaching, social services, the degree of internationalization, employability of graduates and other important parameters are mostly disregarded (Marginson, 2014; Saisana et al., 2011). And this is exactly why ARWU is so frequently criticized. Another obvious bias is favoring natural and technical sciences; same applies to research publications in English. The Nobel Prize indicator affects many really good standing universities located in developing countries, since Nobel Prize winners are mostly affiliated 
to developed countries. Generally speaking, diversity of academic fields and other scholars' achievements seems to be very much underrepresented in these rankings (Huang, 2011; Marginson, 2014).

What concerns QS and THE rankings, the most problematic point are subjectivity of the reputation surveys as well as some of the teaching indicators. Both are causing much instability in the rankings. Having expert-based surveys as one of the ranking indicators is by default subjective to bias because it stems from human opinions and judgments, while the relevant of expertize is actually hard to define and measure (Salmi \& Saroyan, 2007). In other words, subjectivity of ranking indicators is inevitable, even when the indicators themselves seem to be more or less objective. What concerns teaching criteria, Amsler et al. (2012) wrote that in the QS ranking there is only one indicator - the staff-to-student ratio. It is obviously quantitative in nature, and has literally no relation to teaching performance. Of course, this number indirectly can tell us something about the size of classes in an institution but it just cannot accurately tell us much about teaching quality, relevance of teaching, types of learning activities or anything else concerning contents of teaching/learning.

Same questionable would be the parameter of teaching effectiveness in THE system, even though the latter also adds other indicators, such as PhDs, the doctoral-bachelor ratio, facilities and income of institutions and some others.

Fluctuations in the ranking results are partially predetermined by the frequency of changes in ranking methodologies (Marginson, 2014; Saisana et al., 2011). Aguillo et al. (2010) showed that differences between THE and QS rankings are very high for a whole range of the selected years in comparison. This means that both THE and QS systems are unstable as compared to ARWU ranking.

All three ranking methodologies have their impact on ranking results, on the overall score and on the rankings of separate universities. Determining which indicators specifically best predict the overall rankings of universities seems to be both interesting and useful for the universities themselves.

\section{Research Method}

\section{Data sources}

All data were collected directly from QS, ARWU and THE rankings. For the purposes of our analysis, we have chosen top-100 universities from each of these three rankings, as of 2013-2014. All data was copied directly from the official websites. We have collected the scores for every criterion as well as overall scores of the 100 institutions. Since Harvard University is always taken as the benchmark in the ARWU system, it was excluded from our data.

\section{Data analysis}

We have applied secondary data analysis and then regression analysis. The latter was used to explore the effects of independent variables on the output variable. For each ranking, we also used bivariate regression to examine the effect from a single indicator on the ranking separately. Finally, we have employed multiple regressions while observing the impact from the whole set of indicators. 


\section{FACTORS OF HIGHER EDUCATION INSTITUTIONS RANKING}

\section{Results and Their Comparison}

All Pearson correlation coefficients between the single indicator and the ranking of a university overall for all three rankings were negative. The reason for this is that the increase of numerical values means more attention to the indicators but not to higher ranking of institutions.

Instead of indicating relative significance between positive and negative correlations, this shows that the indicators and the overall rankings under all three systems move in the opposite direction. According to our results, all correlation coefficients turned out to be statistically significant in the rankings by ARWU and QS, while some were nil within the THE system.

\section{Conclusions}

Today we can easily observe the increasing competition between universities and colleges at both domestic and international levels. For this and other reasons, the number of university ranking systems is also increasing. Rankings are often seen as a good-quality and useful representation of academic excellence and institutional reputation. Therefore, the increasing numbers of universities are doing their best to get included in institutional rankings.

The major goal of any international university rankings is to provide sufficient information for the decision-making of future students and their parents. However, the actual, today's use of these rankings has changed significantly. Today, university rankings also serve as tools in assessment of universities' performance. They are also instruments in marketing and positioning of universities within countries and worldwide. To some extent, they even became the tools of political influence (Bowman \& Bastedo, 2011) and a leverage for status control (Marginson, 2014). In other words, what seems to be just the numbers in a table has turned out to be a competitive advantage for the whole cities, regions and countries.

Our intention here is not to expose all the weaknesses and biases of the world university rankings but rather to demonstrate that international rankings should not be taken for granted and should be carefully examined since their results require much more attentive and careful interpretation as it was expected. All three ranking systems studied here are far from being perfect when it comes to measuring institutional performance and awarding certain statuses. After analysing the contributions of specific indicators into the final ranking of universities in all three cases, we have obtained several quite interesting findings.

First, most of the indicators in all three systems turned out to be positively correlated with the overall rankings except for the international outlook and industry income indicators in the THE ranking. The reason why these indicators were not statistically significant might be related to their lower assigned weights and whether the universities were really providing accurate information on their financing and degree of internationalization. We need to highlight here that there is clearly a need for the authorities publishing such rankings to be aware how sensitive such methodological issues can be. Moreover, in our opinion, transparency of financial reporting and internationalization data should be followed very strictly.

Secondly, we need to mention that in all three rankings, not all indicators contribute to the final ranking results of the universities. In simple terms, this implies that university 
rankings might be determined by a few indicators only. Differences in methodological approaches may cause vulnerabilities in seemingly objective evaluations. However, as it was well noted by (Rauhvargers, 2011), the audience of such rankings seldom fully understand the actual information on how inside and complex calculations form the final rankings. This causes the situation when readers perceive the presented information as they want and then feel misinformed. Even more, the audience may both overestimate or underestimate the contributions of some indicators into the final ranking.

As the concluding remark, we would like to caution all stakeholders in the sector of higher education, at all its levels, against lightweight and easy use and interpretation of the numbers published in the ranking. On a higher level, public decisions should never be based solely on global rankings, despite how objective they claim to be. We can also suggest that all the indicators selected by the ranking committees should be regularly revised to avoid the potential biases.

\section{References:}

Aguillo, I. F., Bar-Ilan, J., Levene, M., \& Ortega, J. L. (2010). Comparing university rankings. Scientometrics, 85(1), 243-256.

Altbach, P. G. (2012). The globalization of college and university rankings. Change: The Magazine of Higher Learning, 44(1), 26-31.

Amsler, S. S., \& Bolsmann, C. (2012). University ranking as social exclusion. British Journal of Sociology of Education, 33(2), 283-301.

Bastedo, M. N., \& Bowman, N. A. (2011). College rankings as an interorganizational dependency: Establishing the foundation for strategic and institutional accounts. Research in Higher Education, 52(1), 3-23.

Bowman, N. A., \& Bastedo, M. N. (2011). Anchoring effects in world university rankings: Exploring biases in reputation scores. Higher Education, 61(4), 431-444.

Carroll, D. (2014). An investigation of the relationship between university rankings and graduate starting wages. Journal of Institutional Research, 19(1), 46-54.

Deem, R., Mok, K. H., \& Lucas, L. (2008). Transforming higher education in whose image? Exploring the concept of the 'world-class' university in Europe and Asia. Higher Education Policy, 21(1), 83-97.

Hazelkorn, E. (2009). Rankings and the battle for world-class excellence: Institutional strategies and policy choices. Higher Education Management and Policy, 21(1), 55- 76.

Hazelkorn, E. (2014). Reflections on a decade of global rankings: What we've learned and outstanding issues. European Journal of Education, 49(1), 12-28.

Huang, M.-H. (2011). A comparison of three major academic rankings for world universities: From a research evaluation perspective. Journal of Library and Information Studies, 9(1), 1-25.

Lo, W. Y. W. (2011). Soft power, university rankings and knowledge production: Distinctions between hegemony and self-determination in higher education. Comparative Education, 47(2), 209-222.

Marginson, S. (2014). University rankings and social science. European Journal of Education, 49(1), $45-59$.

Proulx, R. (2007). Higher education ranking and leagues tables: Lessons learned from benchmarking. Higher Education in Europe, 32(1), 71-82.

Rauhvargers, A. (2011). Global university rankings and their impact. Belgium: European University Association.

Saisana, M., d'Hombres, B., \& Saltelli, A. (2011). Rickety numbers: Volatility of university rankings and policy implications. Research Policy, 40(1), 165-177. 


\section{FACTORS OF HIGHER EDUCATION INSTITUTIONS RANKING}

Salmi, J., \& Saroyan, A. (2007). League tables as policy instruments: Uses and misuses. Higher education management and policy, 19(2), 31-68.

Paper submitted

Paper accepted for publishing

Paper published online
25 February 2019

14 April 2019

25 June 2019 